\title{
VERTICAL SEPARATION OF THE ATMOSPHERIC AEROSOL COMPONENTS BY USING POLIPHON RETRIEVAL IN POLARIZED MICRO PULSE LIDAR (P-MPL) MEASUREMENTS: CASE STUDIES OF SPECIFIC CLIMATE-RELEVANT AEROSOL TYPES
}

\author{
Carmen Córdoba-Jabonero $^{1 *}$, Michaël Sicard ${ }^{2,3}$, Albert Ansmann ${ }^{4}$, Ana del Águila ${ }^{1}$, and Holger
} Baars $^{4}$

${ }^{1}$ Instituto Nacional de Técnica Aeroespacial (INTA), Atmospheric Research and Instrumentation Branch, Torrejón de Ardoz (Madrid), Spain, *cordobajc@inta.es

${ }^{2}$ Remote Sensing Laboratory, Universitat Politècnica de Catalunya (UPC), Barcelona, Spain

${ }^{3}$ Ciències i Tecnologies de l'Espai - Centre de Recerca de l'Aeronàutica i de l'Espai/Institut d'Estudis Espacials de Catalunya (CTE-CRAE/IEEC), Universitat Politècnica de Catalunya, Barcelona, Spain

${ }^{4}$ Leibniz Institute for Tropospheric Research (TROPOS), Leipzig, Germany

\begin{abstract}
POLIPHON (POlarization-LIdar PHOtometer Networking) retrieval consists in the vertical separation of two/three particle components in aerosol mixtures, highlighting their relative contributions in terms of the optical properties and mass concentrations. This method is based on the specific particle linear depolarization ratio given for different types of aerosols, and is applied to the new polarized Micro-Pulse Lidar (P-MPL). Case studies of specific climate-relevant aerosols (dust particles, fire smoke, and pollen aerosols, including a clean case as reference) observed over Barcelona (Spain) are presented in order to evaluate firstly the potential of P-MPLs measurements in combination with POLIPHON for retrieving the vertical separation of those particle components forming aerosol mixtures and their properties.
\end{abstract}

\section{INTRODUCTION}

It is widely known that aerosols contribute to the climate change due to their effects in the radiative balance of the atmosphere. However, particular types of aerosols (dust, marine, pollution, smoke, volcanic ash, pollen, ...) present specific properties, contributing in a different way to climate implications [1].

Lidar depolarization measurements together with the lidar ratio (LR) estimations make possible the classification of aerosols according to their type. Besides, polarized Raman (inelastic) lidar systems can separate independently the extinction from the scattering, fact that, in addition to their depolarization elements, can also give more information on the properties of the aerosols. In our case, a polarized Micro-Pulse Lidar (P-MPL), the standard system within NASA/MPLNET (Micro Pulse Lidar NETwork, mplnet.gsfc.nasa.gov), is routinely in operation at two Spanish aerosol lidar stations: UPC/Barcelona-BCN (NE Iberian Peninsula, IP) and INTA/El Arenosillo-ARN (Huelva, SW IP). The P-MPL is an elastic (no Raman) and monochromatic $(532 \mathrm{~nm})$ system which includes also a depolarization-sensitive channel. The system operates in an automatic and continuous 24/7 mode.

$\mathrm{BCN}$ and ARN sites are located, respectively, in a coastal urban and coastal rural environment. Hence, the 'aerosol mixing' is relatively high at both stations, and then the inversion of the aerosol properties from lidar measurements becomes crucial, requiring the application of determined methods. In particular, the retrieval of their optical properties with an elastic and monochromatic lidar, as the P-MPL, is carried out using the wellknown Klett-Fernald inversion algorithm (KF method, [2, 3]). This retrieval method is applied to the vertical profiles of the lidar backscattered signal in synergy with simultaneous sunphotometer measurements that provide ancillary data of the Aerosol Optical Depth (AOD), that is the constraint condition of the $\mathrm{KF}$ inversion convergence (i.e., [4]). 
Regarding the microphysical properties, retrieval procedures like LIRIC, GARRLiC, GRASP, etc. are more demanding on the lidar performance requirements and cannot be applied to P-MPL measurements. Hence, we use the POLIPHON (POlarization-LIdar PHOtometer Networking) method [5, 6], developed in the Leibniz Institute for Tropospheric Research (TROPOS, www.tropos.de). POLIPHON retrieval consists in the vertical separation of a maximum of three components in aerosol mixtures of aerosol types with clearly different particle depolarization ratios (see more details in [5]).

The aim is to make use of the potential of P-MPLs measurements in combination with POLIPHON in order to: 1) provide a vertical component discrimination of the aerosol mixtures; 2) retrieve their properties; and 3) evaluate their radiative forcing. The systematic application of POLIPHON to P-MPL measurements could yield an interesting climatology in view of those aerosols affecting the climate change. In addition, our findings open perspectives for CALIPSO/CALIOP (Cloud-Aerosol Lidar with Orthogonal Polarization) observations, since it is also an elastic polarized lidar.

Case studies of specific climate-relevant aerosols, dust, fire smoke, pollen and clean conditions (reference case), observed over $\mathrm{BCN}$ are examined. Results will be extrapolated to the aerosol observations to be performed over ARN, where the P-MPL system was recently deployed.

\section{METHODOLOGY}

\subsection{Measurement station and lidar system}

Barcelona (BCN) station is located at the North East Iberian Peninsula $\left(41.4^{\circ} \mathrm{N}, 2.1^{\circ} \mathrm{E}, 115 \mathrm{~m}\right.$ a.s.l.), by the coast of the Mediterranean Sea, in the North campus of the Universitat Politècnica de Catalunya (UPC). A P-MPL is in routine operation since 2014. The system acquires vertical aerosol profiles with a relatively high frequency $(2500 \mathrm{~Hz})$ using a low-energy $(\sim 7 \mu \mathrm{J}) \mathrm{Nd}$ :YLF laser at $532 \mathrm{~nm}$. Polarization capabilities rely on the signal registered at both the co- and cross channels. The P-MPL signal follows the NASA/MPLNET requirements of 1-min integrating time and $15 \mathrm{~m}$ vertical resolution. $\mathrm{BCN}$ is also a NASA/AERONET site.
Parallel and perpendicular P-MPL range-corrected signals (p-RCS and s-RCS, respectively) are obtained from [7]. The volume linear depolarization ratio $\left(\delta^{\mathrm{v}}\right)$ is obtained from the ratio of s-RCS to p-RCS. The particle linear depolarization ratio $\left(\delta_{\mathrm{p}}\right)$ is calculated by the procedure shown in [8]. The total particle backscattering coefficient $\left(\beta_{\text {total }}\right)$ is obtained by applying the KF algorithm [2,3] to the total RCS (=p-RCS+s-RCS), constrained to the AERONET AOD. In this study, AERONET data (AOD and the Ångström exponent, AEx) have been hourly averaged in order to coincide with the hourly averaging applied to P-MPL measurements.

\subsection{POLIPHON method}

POLIPHON procedure can be applied in 1 or 2 steps, retrieving the separation of two or three components in aerosol mixtures, respectively. In particular, the 2-step version is only used for the dust case in order to obtain the separation of three components: dust coarse, dust fine and non-dusty aerosols; otherwise, the discrimination is only performed for two components. POLIPHON details can be found in $[5,6]$. Table 1 shows the POLIPHON version (1-step or 2-step) used in each aerosol mixture case, in addition to the particular $\delta_{\mathrm{i}}$ values assumed for each specific aerosol component $(\mathrm{i}=1,2,3$, depending on the number of separated components, regarded as 'pure' aerosols) $[5,6,9,10]$ presented in this work: dust, fire smoke and pollen (a clean case is also included for reference).

Table 1. Aerosol cases, date of the event (time shown in Figures 1 and 2), AERONET data at that time, and parameters used in the POLIPHON retrieval algorithm.

\begin{tabular}{|c|c|c|c|c|c|c|c|c|c|}
\hline \multirow[b]{2}{*}{$\begin{array}{c}\text { Aerosol } \\
\text { case }\end{array}$} & \multirow[b]{2}{*}{ Date } & \multirow[b]{2}{*}{$\begin{array}{l}\text { Time } \\
\text { (UTC) }\end{array}$} & \multicolumn{2}{|c|}{$\begin{array}{l}\text { AERONET } \\
\text { data }\end{array}$} & \multirow{2}{*}{$\begin{array}{c}\text { POLIPHON } \\
\text { retrieval } \\
\left({ }^{*}\right)\end{array}$} & \multicolumn{4}{|c|}{$\begin{array}{l}\text { Linear depolarization ratio for } \\
\text { each aerosol component }\end{array}$} \\
\hline & & & AOD & AEx & & $\delta_{1}$ & $\delta_{2}$ & $\delta_{3}$ & Ref. \\
\hline DUST & 05 July 2016 & $\begin{array}{l}\text { 03:00 } \\
15: 00\end{array}$ & $\begin{array}{l}0.33 \\
0.29\end{array}$ & $\begin{array}{l}0.52 \\
1.78\end{array}$ & 2-step & 0.39 & 0.16 & 0.05 & {$[5,6]$} \\
\hline SMOKE & $\begin{array}{l}23 \text { May } \\
2016\end{array}$ & 06:00 & 0.14 & 1.32 & 1-step & 0.15 & 0.05 & --- & [9] \\
\hline POLLEN & $\begin{array}{l}23 \text { March } \\
2016\end{array}$ & $15: 00$ & 0.10 & 1.74 & 1-step & 0.40 & 0.05 & -- & [10] \\
\hline CLEAN & $\begin{array}{c}08 \\
\text { November } \\
2016\end{array}$ & 15:00 & 0.04 & 1.33 & 1-step & 0.05 & 0.01 & --- & {$[5,6]$} \\
\hline
\end{tabular}

(*) 1-step: Separation of two aerosol components.

2-step: Separation of three aerosol components.

The contribution of each aerosol component is expressed in terms of the relative ratio between the specific height-integrated backscattering 
coefficient $\left(\beta_{\mathrm{i}}\right)$ for each aerosol component and $\beta_{\text {total }}$, i.e., the relative $\beta_{i} / \beta_{\text {total }}$ ratio (in $\%$ ), and calculated along the day.

\section{RESULTS}

\subsection{Dust case}

A dusty event occurred over BCN station on 5 July 2016. Dust incidence is mostly observed for the first half of the day with a high loading of large particles. They seem to be almost completely removed for the second part of the day, and only smaller dust particles and non-dusty aerosols are present.
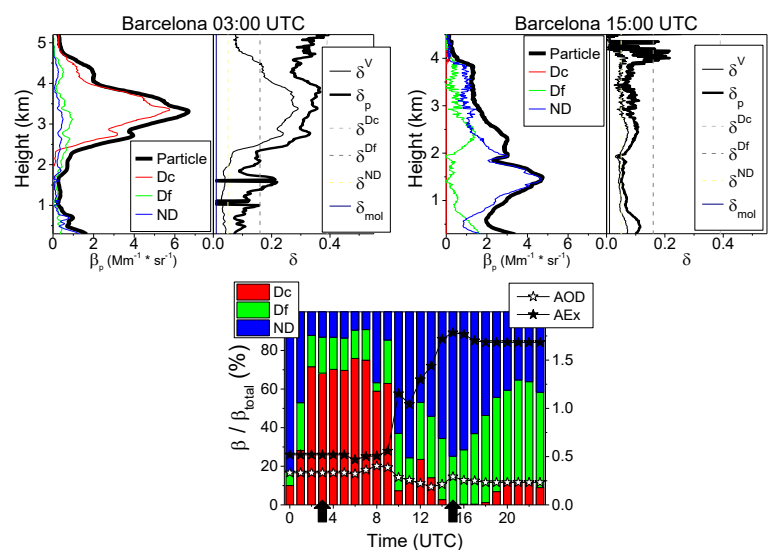

Figure 1. Dust case. (Up) Both vertical backscattering coefficient $\left(\beta_{p}\right.$ ) (total particle and for each specific component, left panels), and linear depolarization ratio (volume, $\delta^{V}$, and particle, $\delta_{p}$, right panels) at 03:00 UTC (left) and 15:00 UTC (right). (Down) Evolution of the relative contribution of each aerosol component, $\beta / \beta_{\text {total }}(\%)$, along the day. (Note: Dc - dust coarse; Df - dust fine, and ND - non-dusty aerosols). The time of those profiles shown in the upper panels are marked by black arrows. Daily AERONET/AOD and AEx values are also included (white and black stars, respectively).

These results are shown in Figure 1, where the daily evolution of the three separated aerosol components (in relative percentage respect to the total backscattering coefficient) (Fig. 1 down) is shown. In addition, the vertical profiles of both the total and the three separated backscattering coefficients (Dc and Df denote, respectively, dust coarse and fine particles, and ND is for non-dusty aerosols) (left panels) together with both the volume and particle linear depolarization ratios $\left(\delta^{\mathrm{V}}\right.$ and $\delta_{\mathrm{p}}$, respectively) (right panels) are also sown in Figure 1 at two moment of the day: 03:00 UTC with high coarse dust presence (Fig. 1, up- left), and 15:00 UTC (no dust coarse) (Fig. 1, upright).

AERONET/AOD and AEx values reported along the day (night-time data are assumed equal to the first and last daytime values in each case) also confirm these results; in particular, AEx is close to 0.5 (coarse particles predominance) and higher than 1.5 (fine particles predominance), respectively, in the first and second part of day. AERONET values are also included in Table 1.

\subsection{Smoke, pollen and clean cases}

Smoke, pollen and clean episodes were observed over BCN station on 23 May 2016, 23 March 2016 and 8 November 2016, respectively. In all these cases, a 1-step POLIPHON retrieval is used to separate the aerosol mixtures in two components. Particle linear depolarization ratio values for each 'pure' aerosol case are shown in Table 1. As for the dusty case, the evolution of the relative percentage between aerosol components in terms of the backscattering coefficient is shown in Figure 2 (right) (the same as illustrated in Figure 1), together to the vertical profiles of the backscattering coefficients and linear depolarization ratios at a given moment of the day (Fig. 2-left).
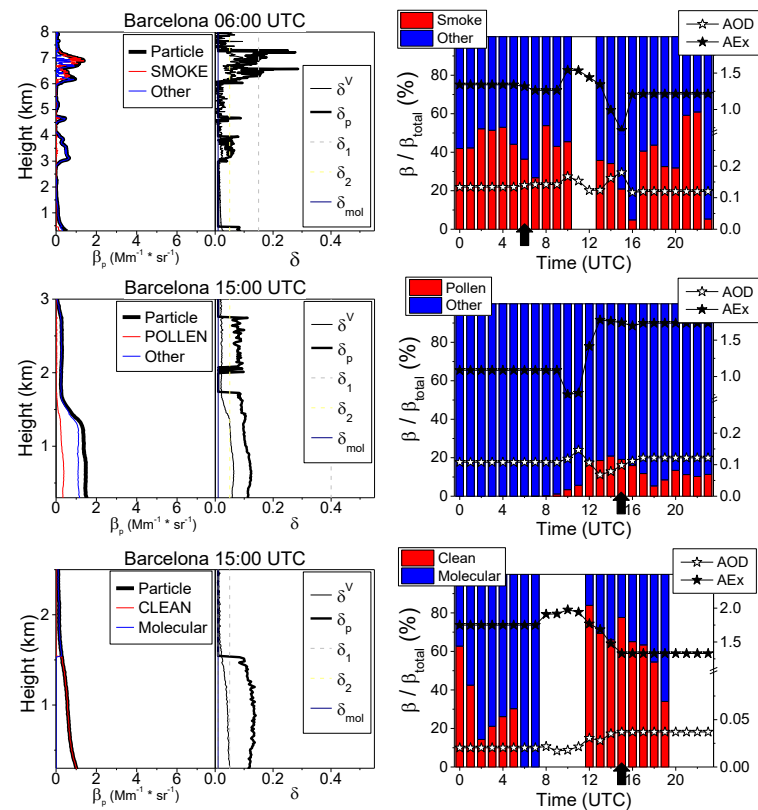

Figure 2. The same as Fig. 1, but for all other cases (from top to bottom panels): fires smoke, pollen and clean conditions. 
In the smoke case, a high proportion of smoke particles are detected in a layer between 6 and 7.5 $\mathrm{km}$ height. They are observed almost during all the day, corresponding to a 50\%, approximately, out of total aerosol loading. In addition, results reflect that the AEx parameter decreases just when the smoke contribution also decreases from around 13:00 to 16:00 UTC (see Fig. 2-up).

Pollen particles (Fig. 2-center) are found no higher than $1.5 \mathrm{~km}$ height over the surface and from around 10:00 UTC on, but with a contribution no higher than $20 \%$. The morning increase of AEx might be due to the formation of local, urban aerosols which are much smaller particles compared to pollen grains. Although at the same time $\beta / \beta_{\text {total }}$ also increases, this result suggests that local aerosols (and not pollen) dominate the columnar-averaged optical properties.

The clean case (see Fig. 2-down) shows that local aerosols are responsible of the background clean conditions in the BCN surroundings (AOD < 0.05). Indeed, the presence of these local aerosols is mostly observed for the daytime period.

\section{CONCLUSIONS}

Four different aerosol mixture cases have been examined: dust, smoke and pollen, and clean conditions as reference. Good results were achieved in the component separation of aerosol mixtures by applying POLIPHON retrieval to PMPL measurements. The evolution of the relative aerosol contribution retrieved along the day for each aerosol component is also plausible in comparison with AERONET data. However, assuming a given value for the linear depolarization ratio for 'pure' aerosols is crucial in that retrieval. Further cases of aerosol mixtures are on-going studied.

\section{ACKNOWLEDGEMENTS}

This work is supported by the Spanish Ministerio de Economía y Competitividad (MINECO) under grant CGL2014-55230-R. Lidar measurements in Barcelona were supported by the ACTRIS (Aerosols, Clouds, and Trace Gases Research Infrastructure Network) Research Infrastructure Project funded by the European Union's Horizon 2020 research and innovation programme (grant agreement n. 654169); by the Spanish MINECO (project TEC2015-63832-P) and the Spanish Ministry of Science and Innovation (project UNPC10-4E-442) and EFRD (European Fund for Regional Development); by the Department of Economy and Knowledge of the Catalan autonomous government (grant 2014 SGR 583).

\section{References}

[1] Myhre et al, 2013: Anthropogenic and natural radiative forcing. In: Stocker et al. (Eds.), Climate Change 2013: The Physical Science Basis. Contribution of Working Group I to the Fifth Assessment Report of the Intergovernmental Panel on Climate Change. Cambridge University Press, Cambridge, NY, USA.

[2] Fernald, 1984: Analysis of atmospheric lidar observations: some comments, Appl. Optics, 23, 652-653.

[3] Klett, 1985: Lidar inversion with variable backscatter/extinction ratios, Appl. Optics, 24, 1638-1643.

[4] Córdoba-Jabonero et al., 2014: Lidar Ratio discrimination retrieval in a two-layer aerosol system from elastic lidar measurements in synergy with sun-photometry data. In: Proceedings of the International Conference in Atmospheric Dust, ProScience, 1, 243-248.

[5] Tesche et al., 2011: Profiling of Saharan dust and biomass-burning smoke with multiwavelength polarization Raman lidar at Cape Verde, Tellus B, 63 (4), 649-676.

[6] Ansmann et al., 2012: Profiling of fine and coarse particle mass: case studies of Saharan dust and Eyjafjallajokull/Grimsvotn volcanic plumes, Atmos. Chem. Phys., 12, 9399-9415.

[7] Flynn et al., 2007: Novel polarization-sensitive micropulse lidar measurement technique, Optics Express, 15 (6), 2785-2790.

[8] Cairo et al., 1999. Comparison of various depolarization parameters measured by lidar, Appl. Optics, 38, 4425-4432.

[9] Burton et al., 2012: Aerosol classification using airborne High Spectral Resolution Lidar measurements - methodology and examples, Atmos. Meas. Tech., 5, 73-98.

[10] Sicard et al., 2016: Near-surface and columnar measurements with a micro pulse lidar of atmospheric pollen in Barcelona, Spain, Atmos. Chem. Phys., 16, 6805-6821. 